\title{
Macrophage migration inhibitory factor is an early marker of severe acute pancreatitis based on the revised Atlanta classification
}

\author{
Dingcheng Shen ${ }^{1}$, Caixi Tang ${ }^{1}$, Shuai Zhu² and Gengwen Huang ${ }^{2 *}$
}

\begin{abstract}
Background: Various serum markers for early identification of severe acute pancreatitis (SAP) have been studied. Serum macrophage migration inhibitory factor (MIF) was reported to be correlated with severity of acute pancreatitis (AP) based on the 1992 Atlanta classification. However, MIF has never been proven to be predictive of disease severity based on the revised Atlanta classification (RAC). The potential predictive value of MIF needs to be further validated.

Methods: Consecutive patients with AP within $48 \mathrm{~h}$ after symptom onset and 10 healthy control volunteers were enrolled prospectively. Serum MIF levels were measured by enzyme-linked immunosorbent assay (ELISA). The predictive value of MIF, clinical scores and other serum markers were determined.

Results: Among 143 patients with AP, there were 52 (36.4\%), 65 (45.5\%) and 26 (18.1\%) with mild, moderate and severe disease based on the RAC respectively. Compared with healthy volunteers, serum levels of MIF were significantly higher in AP patients, especially those with SAP $(P<0.001)$. Multivariate regression analysis indicated that increased serum MIF (cut-off $2.30 \mathrm{ng} / \mathrm{ml}, \mathrm{OR}=3.16, P=0.008$ ), IL-6 (cut-off $46.8 \mathrm{pg} / \mathrm{ml}, \mathrm{OR}=1.21, P=0.043$ ), APACHE II score (cut-off 7.5, $\mathrm{OR}=2.57, P=0.011$ ) and BISAP score (cut-off 1.5, $\mathrm{OR}=1.01, P=0.038$ ) were independent risk factors for predicting SAP $(P<0.05)$. By using the area under the receiver operating characteristic (ROC) curve (AUC), MIF (AUC 0.950) demonstrated more excellent discriminative power for predicting SAP than APACHE II (AUC 0.899), BISAP (AUC 0.886), and IL-6 (AUC 0.826).
\end{abstract}

Conclusions: Serum MIF is a valuable early marker for predicting the severity of AP based on the RAC.

Keywords: Macrophage migration inhibitory factor, Severe acute pancreatitis, Prediction, Revised Atlanta classification

\section{Background}

Acute pancreatitis (AP) is a common digestive disease with the potential to cause significant morbidity and mortality. The incidence of AP ranges from 5 to 30 cases per 100,000, and admissions have increased by at least $15 \%$ over the past 10 years $[1,2]$. AP can be categorized

\footnotetext{
*Correspondence: huanggengwen@csu.edu.cn

2 Department of Pancreatic Surgery, General Surgery, Xiangya Hospital,

Central South University, 87 Xiangya Rd, Changsha 410008, Hunan

Province, China

Full list of author information is available at the end of the article
}

into mild acute pancreatitis (MAP), moderately severe acute pancreatitis (MSAP), and severe acute pancreatitis (SAP) according to the revised Atlanta classification (RAC) [3]. The majority of cases $(>80 \%)$ is MAP, which is characterized by only interstitial changes of the pancreas without local or systemic complications, and the mortality is quite low. MSAP is characterized by local complications or transient organ failure $(<48 \mathrm{~h})$, with a mortality of less than $5 \%$. However, SAP is characterized with persistent failures of one or more organ system (respiratory, cardiovascular, or renal), and associated with significant morbidity and mortality [2-4]. Therefore, 
early identification of those who would progress to the severe category could allow the physicians to monitor more closely and put more medical resources.

A host of predictors, including clinical and laboratory markers (e.g., C-reactive protein and interleukins 6,8 , and 10) [5-9] and various scoring systems [10, 11], such as Acute Physiology and Chronic Health Evaluation (APACHE) II, Bedside Index for Severity in Acute Pancreatitis (BISAP), Systemic Inflammatory Response Syndrome (SIRS), have been studied to be associated with prediction of severity of AP. However, these predictors are either inconvenient to use or of limited clinical value. Early risk-stratification of AP patients remains a great challenge. There is an urgent clinical need to identify a reliable predictor of disease severity.

Macrophage migration inhibitory factor (MIF) was originally described in 1966 as a cytokine derived from activated $\mathrm{T}$ lymphocytes. It prevented random macrophage migration at the site of inflammation [12]. It belonged to the group of pro-inflammatory cytokines and was considered as a crucial upstream regulator of the innate immune reaction [13, 14]. Previous studies [15-19] reported that increased MIF was associated with several diseases such as rheumatoid arthritis (RA) [15], disseminated intravascular coagulation (DIC) [16], acute respiratory distress syndrome (ARDS) [17], sepsis [18] and other critical illnesses [19]. As for AP, elevations of serum and ascitic MIF levels have been demonstrated in rats with experimental pancreatitis and prophylactic administration of anti-MIF antibody significantly improved the survival rate of the rats [20]. Serum MIF levels were also found to be higher in patients with SAP or with pancreatic necrosis (PN) compared with those with mild attack or without PN [21]. However, to the best of our knowledge, serum MIF has never been proven to be predictive of severity of AP based on the RAC [22, 23]. Therefore, the aim of the present study is to validate the hypothesis that serum MIF might serve as an early marker to predict the severity of AP defined by the RAC.

The study was designed, conducted and reported according to STROBE guidance [24] for observational studies.

\section{Methods}

\section{Patients}

This study was conducted according to the guidelines laid down in the Declaration of Helsinki and all procedures involving human subjects were approved by the Ethics Committee of Xiangya Hospital, Central South University (a tertiary referral center with an average of 300 admissions with AP annually), China (reference: 2019010008). Written informed consent was obtained from all subjects or their representatives for the study participation. Between June 2019 and June 2020, a consecutive cohort of 143 patients diagnosed with AP were recruited and 10 healthy volunteers matched with sex and age were included as control subjects. All patients included in this study were admitted to the hospital within $48 \mathrm{~h}$ of onset of symptoms. Inclusion criterion was: first episode of AP as defined by AGA guideline [1]. Exclusion criteria were: age below 18 or over 80 years; advanced chronic respiratory, renal, heart and immune diseases. All patients received standard conservative treatment according to the latest international guidelines $[1,25,26]$, Patients with organ failure were treated with organ-specific support as needed, including mechanical ventilation, continuous renal replacement therapy, vasoactive agents, and others. Step-up surgical interventions were generally performed in cases of infected pancreatic necrosis (IPN) and, if possible, postponed at least $3 \sim 4$ weeks since disease onset [27].

\section{Definitions}

The diagnosis and classification of AP were based on the RAC and AGA guideline [1,3]. The criteria for organ failure (OF) was defined for 3 organ systems (respiratory, cardiovascular, or renal) on the basis of the worst measurement over a 24-h period. Respiratory failure: $\mathrm{PaO} 2 /$ $\mathrm{FiO} 2 \leq 300 \mathrm{mmHg}(\leq 40 \mathrm{kPa})$ or a need for mechanical ventilation; cardiovascular failure: circulatory systolic blood pressure $<90 \mathrm{mmHg}$, despite adequate fluid resuscitation or need for inotropic agent; renal failure: creatinine $\geq 171 \mu \mathrm{mol} / \mathrm{L}(\geq 2.0 \mathrm{mg} / \mathrm{dL})$ or a need for hemofiltration or hemodialysis. Persistent OF was defined as OF in the same organ system for $48 \mathrm{~h}$ or more. PN was characterized by presence of pancreatic parenchymal necrosis more than $30 \%$ on intravenous contrast enhanced CT performed after 72-h of attack, and IPN was defined as a positive culture of (peri)pancreatic necrotic fluid obtained during the first drainage or necrosectomy. These definitions were all consistent with the AGA guideline on AP [1].

\section{Sample and data collection}

Peripheral venous blood samples were obtained immediately on admission (within $48 \mathrm{~h}$ of onset of symptom) of each patient and each healthy volunteer. Plasma used for testing MIF was obtained after centrifugation $(3000 \times g$, $10 \mathrm{~min}, 4{ }^{\circ} \mathrm{C}$ ) and stored at $-80{ }^{\circ} \mathrm{C}$ for further analysis. Demographic and clinical data were recorded in an electronic database prospectively. APACHE II, BISAP and SIRS scores were calculated within $24 \mathrm{~h}$ of admission. Routine clinical serum markers including white blood cell (WBC), creatinine, fibrinogen, CRP, procalcitonin (PCT), IL-6, IL-10 and tumor necrosis factor- $\alpha$ (TNF- $\alpha$ ) were reported by the Department of Clinical Biochemistry of 
Xiangya hospital. All patients were followed until discharge from the hospital or until death.

\section{Serum MIF assay}

Serum MIF concentration was measured by a quantitative sandwich enzyme linked immunosorbent assay (ELISA) (R\&D Systems, Minneapolis, MN, USA) following the recommended protocols in the supplemental manufacturer's instructions. The range limit of detection was $0.2-16 \mathrm{ng} / \mathrm{mL}$.

\section{Statistical analysis}

Continuous variables were expressed using mean \pm standard deviation (SD) and median \pm interquartile ranges (IQR), and categorical variables were described in absolute numbers and in percentages, in the univariate analysis, the Fisher exact test, the $\chi^{2}$ test, and binary logistic regression analysis were used for bivariate comparisons. Then the significant variables were included in the multivariable analysis, which were performed using logistic regression analysis as we described previously [4]. Receiver operating characteristic (ROC) curves were constructed for predictive variables, and the area under the curve (AUC) with 95 per cent confidence intervals calculated, optimal cut-off values for sensitivity, specificity for each parameter were derived from the ROC curves [5]. All tests were bilateral, and P-values $<0.05$ were considered statistically significant. The SPSS (22.0) was used for all analyses.

\section{Results}

\section{Patient clinical characteristics}

A total of 143 patients with AP (94 men and 49 women) were included in the study. Median age at admission was
47 years old (26-76). Hyperlipidemia was the most common cause $(\mathrm{n}=77,53.8 \%)$, followed by biliary $(\mathrm{n}=46$, $32.2 \%)$, other $(\mathrm{n}=12,8.4 \%)$, and alcoholic $(\mathrm{n}=8,5.6 \%)$. $52(36.4 \%)$ of them had MAP, 65 (45.5\%) had MSAP and 26 (18.1\%) had SAP. PN and IPN occurred in $63(44.1 \%)$ and $7(4.9 \%)$ patients. The overall hospital mortality was $3.5 \%$ (5 of 143).

\section{Prediction of SAP}

One hundred and forty-three patients with AP were divided into two groups according to the presence of persistent $\mathrm{OF}$, ie, non-SAP group (including MAP and MSAP, $n=117)$ and SAP group $(n=26)$, and 10 healthy volunteers were chosen as control group. The demographic characteristics of the 3 groups were similar $(P>0.05)$. The non-SAP and SAP group differed significantly $(P<0.001)$ in terms of PN, mortality and length of hospital stay (Table 1 ).

Compared with control and non-SAP group, clinical biomarkers and scores including neutrophil, BUN, Cr, D-dimer, CRP, PCT, IL-6, MIF, APACHE II, BISAP and SIRS scores were significantly higher in SAP group by the univariate analysis (Table 2).

The variables showing significant predictive value within univariate analysis were included in further stepwise multivariate logistic regression (Table 3). The regression analysis indicated that the increased serum IL-6 (OR $=1.21 ; 95 \% \mathrm{CI}, 1.003-1.274 ; P=0.043)$, MIF $(\mathrm{OR}=3.16 ; 95 \% \mathrm{CI}, 1.225-3.777 ; P=0.008)$, APACHE II score $(\mathrm{OR}=2.57 ; 95 \% \mathrm{CI}, 1.132-3.259 ; P=0.011)$ and BISAP score $(\mathrm{OR}=1.01 ; 95 \% \mathrm{CI}, 1.004-1.015 ; P=0.038)$ were independent risk factors for predicting SAP $(P<0.05)$. Box-whisker plots showed levels of IL-6, MIF,

Table 1 Comparison of baseline characteristics among the patients with different groups

\begin{tabular}{|c|c|c|c|c|}
\hline Parameters & Control $(n=10)$ & non-SAP $(n=117)$ & $\operatorname{SAP}(n=26)$ & $P$ value \\
\hline Age, (mean $\pm S D)$, years & $41.40 \pm 13.90$ & $46.80 \pm 14.74$ & $49.69 \pm 13.85$ & 0.070 \\
\hline Male/Female, $\mathrm{n}$ & $6 / 4$ & $75 / 42$ & $19 / 7$ & 0.761 \\
\hline Etiology, n (\%) & & & & 0.415 \\
\hline Hypertriglyceridemia & & $64(54.8)$ & $13(50.0)$ & \\
\hline Biliary & & $37(31.6)$ & $9(34.6)$ & \\
\hline Alcohol & & $6(5.1)$ & $2(7.7)$ & \\
\hline Other & & $10(8.5)$ & $2(7.7)$ & \\
\hline PN, n (\%) & & $38(32.5)$ & $25(96.2)$ & 0.001 \\
\hline IPN, n (\%) & & $1(0.8)$ & $6(23.1)$ & 0.124 \\
\hline Death, n (\%) & & $0(0.0)$ & $5(19.2)$ & $<0.001$ \\
\hline Hospital stay, (mean $\pm S D), d$ & & $10.33 \pm 5.68$ & $25.63 \pm 25.27$ & $<0.001$ \\
\hline
\end{tabular}

The bold in the table means the $P$ value of these parameters were $<0.05$ and considered statistically significant $P N$ Pancreatic necrosis, IPN Infected pancreatic necrosis, SD standard deviations Categorical variables are described as N (\%) 
Table 2 Comparison of clinical biomarkers and scores in different groups

\begin{tabular}{|c|c|c|c|c|}
\hline Parameters & Control $(n=10)$ & Non-SAP $(n=117)$ & $\operatorname{SAP}(n=26)$ & $P$ value \\
\hline $\operatorname{WBC}\left(\times 10^{9} / \mathrm{L}\right)$ & $5.52 \pm 2.57$ & $12.54 \pm 4.58$ & $14.28 \pm 3.62$ & 0.166 \\
\hline Neutrophil count $\left(\times 10^{9} / \mathrm{L}\right)$ & $4.01 \pm 2.13$ & $10.12 \pm 4.07$ & $12.42 \pm 3.21$ & 0.041 \\
\hline Lymphocyte count ( $\left.\times 10^{9} / \mathrm{L}\right)$ & $2.13 \pm 1.04$ & $1.66 \pm 1.73$ & $0.96 \pm 0.40$ & 0.115 \\
\hline NLR & $3.64 \pm 2.14$ & $9.88 \pm 6.32$ & $15.76 \pm 8.52$ & 0.003 \\
\hline $\mathrm{HCT}(\%)$ & $42.33 \pm 3.78$ & $40.26 \pm 6.20$ & $37.94 \pm 9.69$ & 0.251 \\
\hline BUN (mmol/L) & $4.67 \pm 2.17$ & $5.09 \pm 3.44$ & $11.83 \pm 6.74$ & $<0.001$ \\
\hline $\mathrm{Cr}(\mathrm{umol} / \mathrm{L})$ & $67.23 \pm 18.55$ & $80.69 \pm 25.39$ & $182.03 \pm 123.13$ & $<0.001$ \\
\hline D-dimer (mg/L) & $0.32 \pm 0.21$ & $1.41 \pm 1.81$ & $3.85 \pm 4.29$ & 0.001 \\
\hline Fibrinogen (g/L) & $3.21 \pm 0.67$ & $4.99 \pm 1.72$ & $5.73 \pm 1.60$ & 0.127 \\
\hline $\mathrm{CRP}(\mathrm{mg} / \mathrm{L})$ & $5.32 \pm 4.26$ & $151.16 \pm 105.05$ & $303.03 \pm 222.40$ & 0.017 \\
\hline PCT (ng/L) & $0.36 \pm 0.12$ & $2.15 \pm 5.54$ & $6.33 \pm 6.72$ & 0.033 \\
\hline IL-6 (pg/ml) & $3.27 \pm 2.59$ & $47.39 \pm 59.21$ & $183.33 \pm 231.23$ & $<0.001$ \\
\hline IL-10 (pg/ml) & $8.23 \pm 3.12$ & $13.29 \pm 31.78$ & $14.41 \pm 20.87$ & 0.896 \\
\hline TNF-a (pg/ml) & $4.24 \pm 2.18$ & $14.08 \pm 8.75$ & $17.96 \pm 9.24$ & 0.126 \\
\hline MIF (ng/ml) & $0.51 \pm 0.23$ & $1.68 \pm 2.04$ & $6.04 \pm 4.05$ & $<0.001$ \\
\hline APACHE ॥ & & $4.40 \pm 3.74$ & $12.19 \pm 4.13$ & $<0.001$ \\
\hline BISAP & & $1.02 \pm 0.77$ & $2.94 \pm 1.29$ & $<0.001$ \\
\hline SIRS & & $2.14 \pm 2.09$ & $4.50 \pm 2.66$ & $<0.001$ \\
\hline
\end{tabular}

The bold in the table means the $P$ value of these parameters were $<0.05$ and considered statistically significant

WBC White blood cell, NLR Neutrophil-lymphocyte ratio, HCT Hematocrit, BUN Blood urea nitrogen, $C r$ Creatinine, CRP C-reactive protein, $P C T$ procalcitonin, IL Interleukin, TNF Tumor necrosis factor, MIF Macrophage migration inhibitory factor, APACHE Acute Physiology And Chronic Health Evaluation, BISAP Bedside Index for Severity in Acute Pancreatitis, SIRS Systemic Inflammatory Response Syndrome

WBC, Neutrophil count, CRP, APACHE II, BISAP and SIRS were expressed as mean \pm standard deviation (SD), other variables-as median \pm interquartile ranges (IQR)

\begin{tabular}{llll}
$\begin{array}{l}\text { Table } 3 \\
\text { for predicting SAP }\end{array}$ & logistic & regression & analysis \\
\hline Parameters & OR & $\mathbf{9 5 \% ~ C l}$ & $P$ value \\
\hline IL-6 & 1.21 & $1.003-1.274$ & $\mathbf{0 . 0 4 3}$ \\
MIF & 3.16 & $1.225-3.777$ & $\mathbf{0 . 0 0 8}$ \\
APACHE II & 2.57 & $1.132-3.259$ & $\mathbf{0 . 0 1 1}$ \\
BISAP & 1.01 & $1.004-1.015$ & $\mathbf{0 . 0 3 8}$ \\
\hline
\end{tabular}

The bold in the table means the $P$ value of these parameters were $<0.05$ and considered statistically significant

IL Interleukin, MIF Macrophage migration inhibitory factor, APACHE Acute Physiology And Chronic Health Evaluation, BISAP Bedside Index for Severity in Acute Pancreatitis, OR Odds ratio, $\mathrm{Cl}$ Confidence intervals

APACHE II and BISAP score in patients with different groups (Fig. 1).

\section{Predictive value of IL-6, MIF, APACHE II and BISAP scores in SAP}

The ROC curves of MIF, APACHE II, BISAP scores and IL-6 were plotted for predicting SAP (Fig. 2). The AUC values were summarized in Table 4. Using the optimal cut-off value of MIF $(2.30 \mathrm{ng} / \mathrm{ml})$, it surpassed all other parameters measured in the present study, with a AUC, sensitivity and specificity of $0.950,96.2 \%$ and $80.3 \%$.

\section{Discussion}

The present prospective cohort study has shown that serum MIF can serve as a valuable early marker to predict the severity of AP within $72 \mathrm{~h}$ of disease onset. It even outperformed APACHE II, BISAP and IL-6. To the best of our knowledge, this study was the first study to identify the early predictive value of serum MIF in the context of the RAC of AP.

AP is a potentially lethal disease with increasing incidence. The clinical course of AP varies greatly among patients, ranging from mild (self-limiting clinical course), through moderate (local complication or transient organ failure) to severe (persistent organ failure) disease. Accurate recognition of the severity is very crucial for the clinical decision-making [3]. For patients with predicted SAP, monitoring in the intensive care unit (ICU), early fluid resuscitation, early enteral nutrition and other interventions would be used, hopefully improving the overall prognosis [1-3]. Thus, with the purpose of early prediction of the severity of AP, a host of serum markers have been tested [6-9].

A recent large cohort study demonstrated that the level of circulating histones within $48 \mathrm{~h}$ after disease onset was an accurate index of disease severity, and capable of predicting persistent OF and mortality 

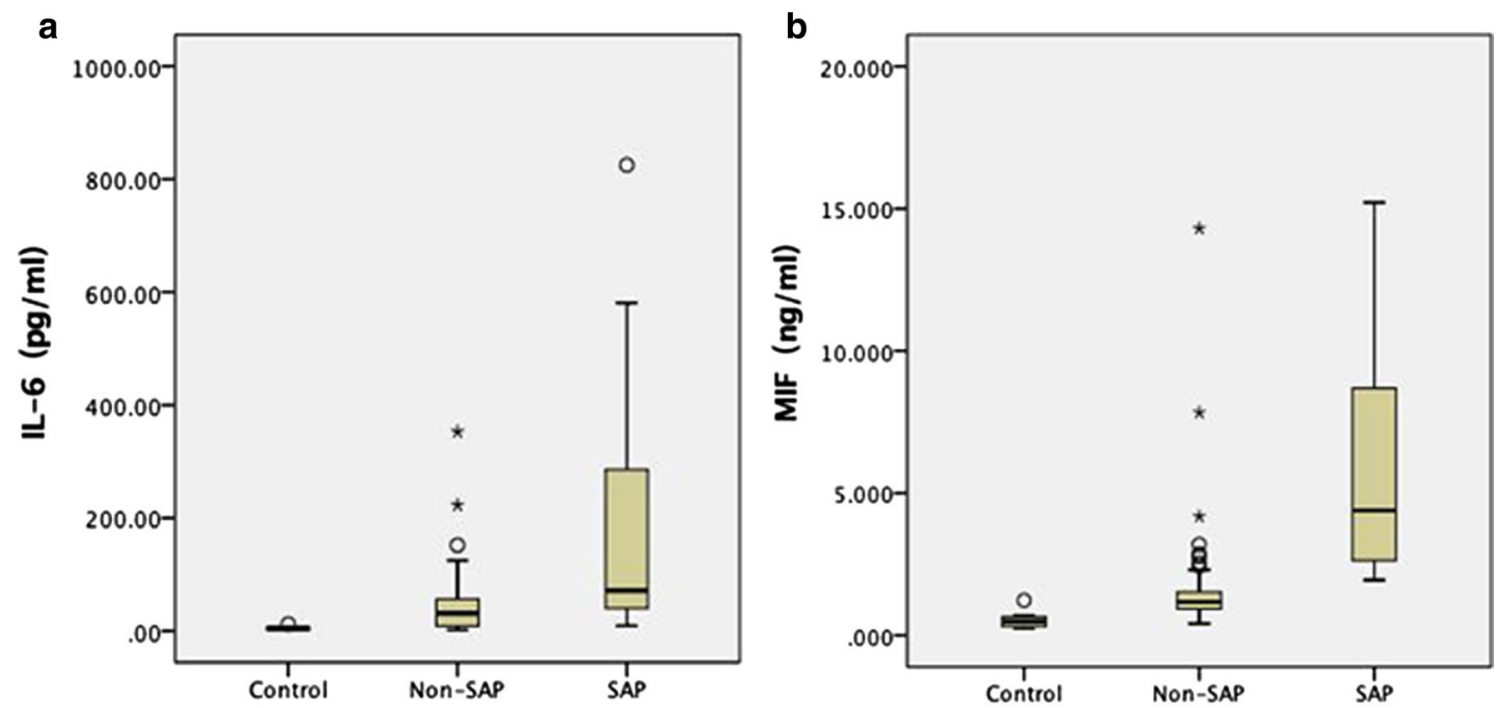

C

d
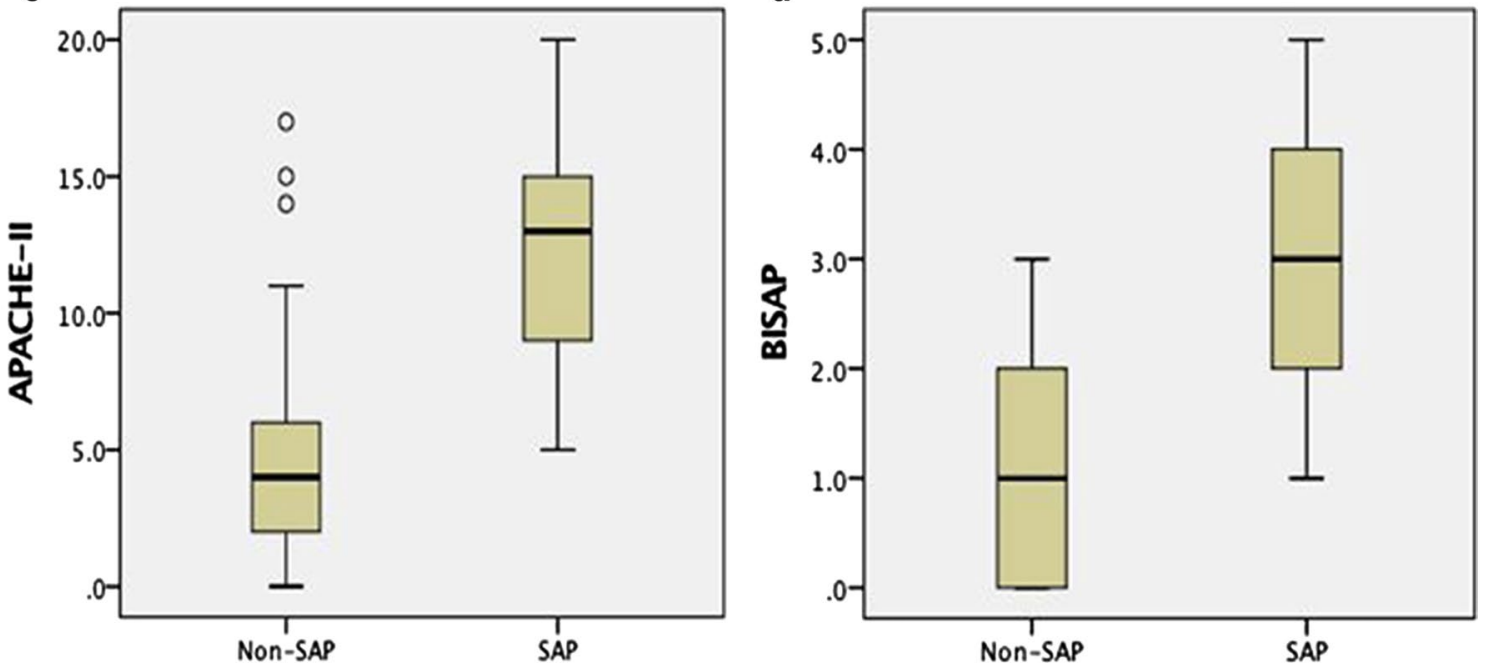

Fig. 1 Box-whisker plots showing levels of IL-6 (a), MIF (b), APACHE II (c) and BISAP (d) score in patients with different severity of AP. Results are expressed as median, with error bars representing the IQR

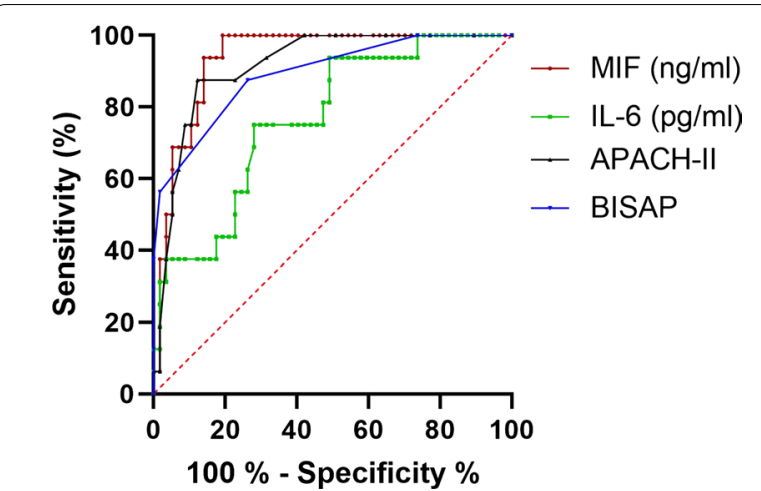

Fig. 2 Receive operating characteristic $(\mathrm{ROC})$ curve for predicting SAP by MIF, APACHE II, BISAP scores and IL-6
[5]. IL-6 had also been studied in detail for its role in severity stratification of AP. A meta-analysis involving 11 studies showed that serum IL-6 on day 1 to 3 after admission had a sensitivity of $81-84 \%$ and specificity between 76 and $85 \%$ for predicting SAP [28]. Jain et al. found that serum IL- $6>160 \mathrm{pg} / \mathrm{ml}$ increased the positive predictive value of persistent SIRS from 56 to $85 \%$ and specificity from 64 to $95 \%$ for predicting SAP and then concluded that a combination of SIRS and IL-6 might be a useful and accurate predictor of severity [29]. In line with Jain's study, this study also revealed that IL-6 was an independent risk factor $(\mathrm{OR}=1.21)$, with modest sensitivity and AUC for predicting SAP. 
Table 4 Accuracy of the studied parameters in predicting SAP

\begin{tabular}{lllll}
\hline Parameters & Cut-off & AUC (95\% Cl) & Sensitivity (\%) & Specificity (\%) \\
\hline IL-6 & $46.8 \mathrm{pg} / \mathrm{ml}$ & $0.826(0.746-0.906)$ & 69.2 & 83.8 \\
BISAP & 1.5 & $0.886(0.820-0.953)$ & 84.6 & 79.5 \\
APACHE II & 7.5 & $0.899(0.820-0.953)$ & 76.9 & 88.0 \\
MIF & $2.30 \mathrm{ng} / \mathrm{ml}$ & $0.950(0.914-0.987)$ & 96.2 & 80.3 \\
\hline
\end{tabular}

Other serum markers, including BUN, CRP, D-dimer, apolipoprotein A-I were widely investigated [29-33]. Nevertheless, none of these serum markers were highly accurate nor specific. Moreover, there were remarkable controversies among studies regarding the effectiveness of these markers.

Meanwhile, multifactorial scoring systems have also been investigated for this purpose such as BISAP and APACHE II, two of the most widely used prognostic scoring systems in AP, particularly used for research purposes. A recent prospective study involving 343 patients revealed that both BISAP (cut-off $\geq 2$, sensitivity $84.1 \%$, specificity 91.9\%, AUC 0.93) and APACHE II (cut-off $\geq 7$, sensitivity 92.3\%, specificity $92.5 \%$, AUC 0.98 ) were comparable in predicting SAP and outperformed other scoring systems [7]. The present study also proved the effectiveness of these 2 scoring systems. However, each of the existing scoring systems had its intrinsic shortcoming such as inconvenience in application in the clinical setting [10]. Physicians always wished that there would be a single marker which could outperform these scoring systems to predict the severity of AP.

MIF belongs to the group of pro-inflammatory cytokines [12]. Since reseachers discovered the inhibitory effects of MIF on T cell migration in vitro, the name "macrophage migration inhibitory factor" was defined. A series of researches demonstrated that MIF was constitutively expressed and stored within the intracellular pools. It could be released into the circulation on stimulation by proinflammatory cytokines, lipopolysaccharide (LPS), and gram-positive exotoxins without de-novo mRNA generation and protein synthesis [13, 14]. Researchers have provided evidences that MIF directly or indirectly promoted the production or expression of a large panel of proinflammatory molecules including TNF- $\alpha$, IL-6, IL-8, IL-12, interferon- $\gamma$ (IFN- $\gamma$ ), nitric oxide (NO), matrix metalloproteinase (MMP) and prostaglandin E2 (PGE2) $[34,35]$. MIF has thus been shown to play an important role as a pivotal regulator of inflammation and innate immunity.

In rodent models, infusion of MIF could lead to multiple organ failure and even death, which could be reversed by anti-MIF antibodies. Elevations of MIF levels in serum and ascites have been demonstrated in experimental pancreatitis and prophylactic administration of anti-MIF antibody significantly improved the survival rate of the rats [20]. In clinical settings, serum MIF levels were elevated in patients with a severe attack of AP, particularly among those who experienced pancreatic necrosis [21]. Similar conclusions were drawn by Sakai and Dambrauskas $[20,36]$. However, in these studies, the classification of the severity of AP was based on the 1992 Atlanta symposium. The biggest difference between 1992 Atlanta classification and 2012 Atlanta classification was the definition of the severe category. Therefore, the role of serum MIF in predicting the severity of AP in the context of current severity classification remains unclear.

This study had several limitations. Firstly, this cohort was conducted at a tertiary care center. Most of the patients with $\mathrm{AP}$ in the institution were referred from other hospitals during the varying course of AP. Among them, only a minority of patients were admitted within $48 \mathrm{~h}$ from disease onset. The relative small population was a limitation of the study. Secondly, in this study, we enrolled patients with AP who were admitted to the hospital within $48 \mathrm{~h}$ from onset of symptoms. Ideally, $48 \mathrm{~h}$ or even $24 \mathrm{~h}$ would be more persuasive to qualify an early predictor. Therefore, further larger studies enrolling a larger number of patients with AP and limiting the time to $24 \mathrm{~h}$ or earlier would be needed. Thirdly, a high number of cases resulting from hypertriglyceridemia as compared to other available studies, as the prevalence of hypertriglyceridemia has increased dramatically in China with unclear reasons. Therefore, the frequency of hypertriglyceridemia-induced acute pancreatitis (HTG-AP) also increased over the years.

\section{Conclusions}

To the best of our knowledge, the present study was the first study to investigate the early predictive value of MIF on the severity of AP based on the RAC. The results showed that serum MIF was elevated in patients with AP when compared with healthy controls. Moreover, at a cutoff value of $2.30 \mathrm{ng} / \mathrm{ml}$ of MIF, SAP was predicted with a sensitivity of $96.2 \%$ and a specificity of $80.3 \%$, indicating that elevated levels of serum MIF (AUC 0.950) was an accurate index of disease severity, and capable of predicting SAP. It even outperformed APACHE II (AUC 0.899), BISAP (AUC 0.886) and IL-6 (AUC 0.826). Given 
that detection of serum MIF is easily available and relatively inexpensive, serum MIF would hopefully become a potential valuable marker for early identification of patients with SAP.

\begin{abstract}
Abbreviations
AP: Acute pancreatitis; APACHE: Acute Physiology and Chronic Health Evaluation; BISAP: Bedside Index for Severity in Acute Pancreatitis; ELISA: Enzyme-linked immunosorbent assay; MIF: Macrophage migration inhibitory factor; OF: Organ failure; RAC: Revised Atlanta classification; SAP: Severe acute pancreatitis; SIRS: Systemic Inflammatory Response Syndrome.
\end{abstract}

\section{Acknowledgements}

Not Applicable.

\section{Authors' contributions}

DS, CT, SZ and GH contributed to this work. DS and SZ analyzed the data. DS wrote the manuscript. All authors read and approved the final manuscript.

\section{Funding}

This study was supported financially by National Natural Science Foundation of China (8180103017), Wu Jieping Medical Foundation (320.6750.17518), Hunan Provincial Science and Technology Department (2017SK50101, 2016SK4006).

\section{Availability of data and materials}

The datasets generated and/or analyzed in the present study are available from the corresponding author on reasonable request.

\section{Ethics approval and consent to participate}

The authors are accountable for all aspects of the work in ensuring that questions related to the accuracy or integrity of any part of the work are appropriately investigated and resolved. The study was conducted in accordance with the Declaration of Helsinki (as revised in 2013). The study protocol and AP biobank were approved by the Ethics Committee of Xiangya Hospital, Central South University, China (reference: 2019010008). Written informed consent was obtained from all subjects or their representatives for the study participation.

\section{Consent for publication}

Not Applicable.

\section{Competing interests}

The authors declare that they have no competing interests.

\section{Author details}

1 Department of Hepatobiliary and Pancreatosplenic Surgery, Zhuzhou Central Hospital, Zhuzhou 412007, Hunan Province, China. ${ }^{2}$ Department of Pancreatic Surgery, General Surgery, Xiangya Hospital, Central South University, 87 Xiangya Rd, Changsha 410008, Hunan Province, China.

Received: 7 November 2020 Accepted: 28 December 2020

Published online: 22 January 2021

\section{References}

1. Crockett SD, Wani S, Gardner TB, Falck-Ytter Y, Barkun AN. American gastroenterological association institute guideline on initial management of acute pancreatitis. Gastroenterology. 2018;154:1096-101.

2. Forsmark CE, Swaroop VS, Wilcox CM. Acute pancreatitis. N Engl J Med. 2016;375:1972-81.

3. Banks PA, Bollen TL, Dervenis C, Gooszen HG, Johnson CD, Sarr MG, et al Classification of acute pancreatitis-2012: revision of the Atlanta classification and definitions by international consensus. Gut. 2013;62:102-11.

4. Shen D, Wang D, Ning C, Lin C, Cao X, Liu Z, et al. Prognostic factors of critical acute pancreatitis: a prospective cohort study. Dig Liver Dis. 2019;51:1580-5.
5. Liu T, Huang W, Szatmary P, Abrams ST, Alhamdi Y, Lin Z, et al. Accuracy of circulating histones in predicting persistent organ failure and mortality in patients with acute pancreatitis. Br J Surg. 2017;104:1215-25.

6. Yang CJ, Chen J, Phillips AR, Windsor JA, Petrov MS. Predictors of severe and critical acute pancreatitis: a systematic review. Dig Liver Dis. 2014;46:446-51.

7. Vasudevan S, Goswami P, Sonika U, Thakur B, Sreenivas V, Saraya A. Comparison of various scoring systems and biochemical markers in predicting the outcome in acute pancreatitis. Pancreas. 2018;47:65-71.

8. Rao SA, Kunte AR. Interleukin-6: an early predictive marker for severity of acute pancreatitis. Indian J Crit Care Med. 2017;21:424-8.

9. He WH, Zhu Y, Zhu Y, Jin Q, Xu HR, Xion ZJ, et al. Comparison of multifactor scoring systems and single serum markers for the early prediction of the severity of acute pancreatitis. J Gastroenterol Hepatol. 2017;32:1895-901.

10. Mounzer R, Langmead CJ, Wu BU, Evans AC, Bishehsari F, Muddana V, et al. Comparison of existing clinical scoring systems to predict persistent organ failure in patients with acute pancreatitis. Gastroenterology. 2012;142:1476-82.

11. Cho YS, Kim HK, Jang EC, Yeom JO, Kim SY, Yu JY, et al. Usefulness of the bedside index for severity in acute pancreatitis in the early prediction of severity and mortality in acute pancreatitis. Pancreas. 2013;42:483-7.

12. Bloom BR, Bennett $B$. Mechanism of a reaction in vitro associated with delayed-type hypersensitivity. Science. 1966;153:80-2.

13. Calandra T, Spiegel LA, Metz CN, Bucala R. Macrophage migration inhibitory factor (MIF) is a critical mediator of the activation of immune cells by exotoxins of gram-positive bacteria. Proc Natl Acad Sci USA. 1998;95:11383-8.

14. Calandra T, Berhhagen J, Mitchell RA, Bucala R. The macrophage is an important and previously unrecognized source of macrophage migration inhibitory factor (MIF). J Exp Med. 1994;179:1895-902.

15. Leech M, Metz C, Hall P, Hutchinson P, Gianis K, Smith M, et al. Macrophage migration inhibitory factor in rheumatoid arthritis: evidence of proinflammatory function and regulation by glucocorticoids. Arthritis Rheum. 1999:42:1601-8.

16. Gando S, Sawamura A, Hayakawa M, Hoshino H, Kubota N, Nishihira J. High macrophage migration inhibitory factor levels in disseminated intravascular coagulation patients with systemic inflammation. Inflammation. 2007;30:118-24.

17. Lai KN, Leung Joseph CK, Metz CN, Lai FM, Bucala R, Lan HY. Role for macrophage migration inhibitory factor in acute respiratory distress syndrome. J Pathol. 2003;199:496-508.

18. Pohl J, Papathanasiou M, Heisler M, Stock P, Kelm M, Hendgen-Cotta UB, et al. Renal replacement therapy neutralizes elevated MIF levels in septic shock. J Intensive Care. 2016;4:39.

19. Rex S, Kraemer S, Grieb G, Emontzpohl C, Soppert J, Goetzenich A, et al. The role of macrophage migration inhibitory factor in critical illness. Mini Rev Med Chem. 2014;14:1116-24.

20. Sakai Y, Masamune A, Satoh A, Nishihira J, Yamagiwa T, Shimosegawa T. Macrophage migration inhibitory factor is a critical mediator of severe acute pancreatitis. Gastroenterology. 2003;124:725-36.

21. Rahman SH, Menon KV, Holmfield JH, McMahon MJ, Guillou JP. Serum macrophage migration inhibitory factor is an early marker of pancreatic necrosis in acute pancreatitis. Ann Surg. 2007;245:282-9.

22. Petrov MS, Windsor JA. Classification of the severity of acute pancreatitis: how many categories make sense? Am J Gastroenterol. 2010;105:74-6.

23. Windsor JA, Johnson CD, Petrov MS, Layer P, Garg PK, Papachristou GI, et al. Classifying the severity of acute pancreatitis: towards a way forward. Pancreatology. 2015;15:101-4.

24. von Elm E, Altman DG, Egger M, Pocock SJ, Gøtzsche PC, Vandenbroucke $J P$, et al. The strengthening the reporting of observational studies in epidemiology (STROBE) statement: guidelines for reporting observational studies. J Clin Epidemiol. 2008;61:344-9.

25. Working Group IAP/APA Acute Pancreatitis Guidelines. IAP/APA evidencebased guidelines for the management of acute pancreatitis. Pancreatology. 2013;13:e1-15.

26. Pezzilli R, Zerbi A, Campra D, Capurso G, Golfieri R, Arcidiacono PG, et al. Consensus guidelines on severe acute pancreatitis. Dig Liver Dis. 2015;47:532-43.

27. Shen D, Ning C, Huang G, Liu Z. Outcomes of infected pancreatic necrosis complicated with duodenal fistula in the era of minimally invasive 
techniques. Scand J Gastroenterol 2019; https://doi.org/10.1080/00365 521.2019.1619831 [Epub ahead of print].

28. Aoun E, Chen J, Reighard D, Gleeson FC, Whitcomb DC, Papachristou GI. Diagnostic accuracy of interleukin-6 and interleukin-8 in predicting severe acute pancreatitis: a meta-analysis. Pancreatology. 2009;9:777-85.

29. Jain S, Midha S, Mahapatra SJ, Gupta S, Sharma MK, Nayak B, et al. Interleukin-6 significantly improves predictive value of systemic inflammatory response syndrome for predicting severe acute pancreatitis. Pancreatology 2018; https://doi.org/10.1016/j.pan.2018.05.002 [Epub ahead of print].

30. Staubli SM, Oertli D, Nebiker CA. Laboratory markers predicting severity of acute pancreatitis. Crit Rev Clin Lab Sci. 2015;52:273-83.

31. Ke L, Ni HB, Tong ZH, Li WQ, Li N, Li JS. D-dimer as a marker of severity in patients with severe acute pancreatitis. J Hepatobiliary Pancreat Sci. 2012;19:259-65.

32. Peng YS, Chen YC, Tian YC, Yang CW, Lien JM, Fang JT, et al. Serum levels of apolipoprotein $\mathrm{A}-\mathrm{l}$ and high-density lipoprotein can predict organ failure in acute pancreatitis. Crit Care. 2015;19:88-96.
33. Zhou CL, Zhang CH, Zhao XY, Chen $\mathrm{SH}$, Liang HJ, Hu CL, et al. Early prediction of persistent organ failure by serum apolipoprotein $\mathrm{A}-\mathrm{I}$ and high-density lipoprotein cholesterol in patients with acute pancreatitis. Clin Chim Acta. 2018;476:139-45.

34. Onodera S, Kaneda K, Mizue Y, Koyama Y, Fujinaga M, Nishihira J. Macrophage migration inhibitory factor up-regulates expression of matrix metalloproteinases in synovial fibroblasts of rheumatoid arthritis. J Biol Chem. 2000;275:444-50.

35. Roger T, David J, Glauser MP, Calandra T. MIF regulates innate immune responses through modulation of Toll-like receptor 4. Nature. 2001;414:920-4.

36. Dambrauskas Z, Giese N, Gulbinas A, Giese T, Berberat PO, Pundzius J, et al. Different profiles of cytokine expression during mild and severe acute pancreatitis. World J Gastroenterol. 2010;16:1845-53.

\section{Publisher's Note}

Springer Nature remains neutral with regard to jurisdictional claims in published maps and institutional affiliations.
Ready to submit your research? Choose BMC and benefit from:

- fast, convenient online submission

- thorough peer review by experienced researchers in your field

- rapid publication on acceptance

- support for research data, including large and complex data types

- gold Open Access which fosters wider collaboration and increased citations

- maximum visibility for your research: over $100 \mathrm{M}$ website views per year

At $\mathrm{BMC}$, research is always in progress.

Learn more biomedcentral.com/submissions 